\title{
ДИССЕКЦИЯ ВНУТРЕННЕЙ СОННОЙ И ПОЗВОНОЧНОЙ АРТЕРИЙ: МОРФОЛОГИЯ, ПАТОФИЗИОЛОГИЯ, ПРОВОЦИРУЮЩИЕ ФАКТОРЫ
}

Л. А. Калашникова 凶, Т. С. Гулевская, А. В. Сахарова, Р. П. Чайковская, М. В. Губанова, М. С. Данилова, А. А. Шабалина, Л. А. Добрынина

Научный центр неврологии, Москва, Россия

Причина и провоцирующие факторы диссекции внутренней сонной и позвоночной (ВСА/ПА) артерий остаются малоизученными. Целью работы было изучить морфологические изменения стенок ВСА/ПА при диссекции, провоцирующие факторы диссекции, клинические признаки и биомаркеры повреждения соединительной ткани (СТ). Обследован 271 больной (средний возраст - 37,0 \pm 10 лет, женщины - 54\%) с диссекцией ВСА/ПА. Провоцирующие факторы диссекции проанализированы у всех больных. Клинические признаки и биомаркеры повреждения СТ (матриксная металлопротеиназа 9, тканевой ингибитор металлопротеиназы, гидроксипролин, сульфатированные гликозаминогликаны) исследованы у 82 больных и 40 здоровых добровольцев. Гистологическое исследование расслоенных и не расслоенных артерий, проведенное в 5 случаях, обнаружило признаки дисплазии артериальной стенки, сходные с таковыми при фибромышечной дисплазии: истончение, расщепление внутренней эластической мембраны, участки фиброза, неправильной ориентировки и некроза миоцитов в медии. Клинические признаки и биомаркеры дисплазии соединительной ткани (ДСТ) были более выражены при диссекции, чем в контроле. Основными провоцирующими факторами диссекции были повороты головы/физическая нагрузка (42\%), травма головы, как правило, легкая (10\%), острая респираторная инфекция, перенесенная в течение предшествующего месяца (14\%). Заключение: дисплазия артериальной стенки служит причиной диссекции ВСАЛПА, которая развивается спонтанно или под действием провоцирующих факторов. Исследование биомаркеров и клинических признаков ДСТ указывает на наличие распространенного десеекта СТ у больных с диссекцией ВСА/ПА.

Ключевые слова: диссекция внутренней сонной и позвоночной артерий, морфологические изменения артериальной стенки, клинические признаки дисплазии соединительной ткани, биомаркеры повреждения соединительной ткани, провоцирующие факторы диссекции

Финансирование: работа выполнена в рамках государственного задания ФГБНУ НЦН.

Информация о вкладе авторов: Л. А. Калашникова, М. В. Губанова - анализ литературы, сбор и обработка материала, обработка полученных данных, написание текста статьи; Т. С. Гулевская, А. В. Сахарова, Р. П. Чайковская, А. А. Шабалина - сбор, анализ и интерпретация данных; М. С. Данилова - подбор участников исследования; Л. А. Добрынина - обработка полученных данных, редактирование текста статьи.

Соблюдение этических стандартов: исследование одобрено этическим комитетом ФГБНУ НЦН (протокол № $12 / 14$ от 10 декабря 2014 г.). Все участники исследования подписали добровольное информированное согласие на участие в исследовании и публикацию результатов.

$\triangle$ Для корреспонденции: Людмила Андреевна Калашникова

Волоколамское шоссе, д. 80, г. Москва, 125367; kalashnikovancn@yandex.ru

Статья получена: 03.09.2019 Статья принята к печати: 19.09.2019 Опубликована онлайн: 03.10.2019

DOI: $10.24075 /$ vrgmu.2019.064

\section{INTERNAL CAROTID AND VERTEBRAL ARTERY DISSECTION: MORPHOLOGY, PATHOPHYSIOLOGY AND PROVOKING FACTORS}

Kalashnikova LA $\bowtie$, Gulevskaya TS, Sakharova AV, Chaykovskaya RP, Gubanova MV, Danilova MS, Dobrynina LA, Shabalina AA

Research Center of Neurology, Moscow, Russia

The causes of internal carotid artery (ICA) and vertebral artery (VA) dissection, as well as its provoking factors, remain understudied. The aim of this paper was to explore morphological changes in the ICANA walls, factors provoking dissection, clinical signs and biomarkers of connective tissue (CT) damage. A total of 271 patients were examined, of whom 54\% were women. The mean age of the participants was $37.0 \pm 10$ years. Clinical signs and biomarkers of CT damage (matrix metalloproteinase 9, tissue inhibitor of metalloproteinase 1, hydroxyproline, sulphated glycosaminoglycans) were analyzed in 82 patients and 40 healthy volunteers. Histologic examination of dissected and seemingly intact arteries conducted in 5 cases revealed signs of arterial wall dysplasia similar to those characteristics of fibromuscular dysplasia: thinning and splitting of the internal elastic membrane, areas of fibrosis, irregular orientation of myocytes, and their necrosis in the tunica media. Clinical signs and biomarkers of CT dysplasia (CTD) were more pronounced in patients with arterial dissection than in the controls. The major provoking factors were head turns and physical activity (42\%), minor head injury (10\%), and acute respiratory infection in the month preceding arterial dissection (14\%). We conclude that arterial wall dysplasia is a predisposing factor for ICANA dissection, both spontaneous and provoked. The analysis of CTD biomarkers and clinical signs suggests connective tissue pathology in patients with ICAVA dissection.

Keywords: internal carotid artery dissection, vertebral artery dissection, morphological changes in the arterial wall, clinical signs of connective tissue dysplasia, biomarkers of connective tissue damage, factors provoking dissection

Funding: this study was part of the state assignment for Research Center of Neurology.

Author contribution: Kalashnikova LA, Gubanova MV — literature analysis, data acquisition, processing of the obtained data, manuscript preparation; Gulveskaya TS, Sakharova AV, Chaykovskaya RP, Shabalina AA — data acquisition, analysis and interpretation; Danilova MS — recruitment of participants; Dobrynina LA — processing of the obtained data, manuscript preparation.

Compliance with ethical standards: the study was approved by the Ethics Committee of Research Center of Neurology (Protocol 12/14 dated December 10, 2014). All study participants consented to participate in the study and to have the results published.

$\triangle$ Correspondence should be addressed: Ludmila A. Kalashnikova

Volokolamskoe shosse, 80, Moscow, 125367; kalashnikovancn@yandex.ru

Received: 03.09.2019 Accepted: 19.09.2019 Published online: 03.10.2019

DOI: 10.24075/brsmu.2019.064

Диссекция (расслоение) внутренней сонной (BCA) и позвоночной артерий (ПА) представляет собой проникновение крови через разрыв интимы из просвета в стенку артерии с распространением между ее слоями и их расслаиванием, что приводит к формированию интрамуральной гематомы (ИМГ), реже - двойного просвета или расслаивающей аневризмы [1]. Сужение или окклюзия просвета артерии под влиянием ИМГ 
служит основной причиной ишемических нарушений мозгового кровообращения. Другим механизмом их развития является артерио-артериальная эмболия тромбами, сформировавшимися в месте разрыва интимы. При отсутствии гемодинамически значимых стенозов единственным клиническим проявлением диссекции может быть шейная и головная боли [1, 2].

До конца прошлого века диссекцию ВСА/ПА считали крайне редкой патологией, поскольку основным методом верификации было патоморфологическое исследование в случаях летального исхода при тяжелом инсульте. Последний при диссекции ВСА/ПА происходит очень редко, что и приводило к ошибочному представлению о раритетности диссекции. После широкого внедрения в клинику методов нейровизуализации, а именно магнитно-резонансной ангиографии (MPA) и компьютернотомографической ангиографии (КТА), а также режимов магнитно-резонансной томографии (МРТ), позволяющих визуализировать ИМГ, стало очевидным, что диссекция ВСА/ПА служит основной причиной ишемического инсульта в молодом возрасте, а также причиной шейной и головной болей, которые часто не распознают или диагностируют с большим опозданием [1, 3-7].

Целенаправленное изучение диссекции артерий, кровоснабжающих головной мозг, в нашей стране впервые было начато в Научном центре неврологии в конце 1990-х гг. почти одновременно с исследованиями, проводимыми за рубежом. Несмотря на успехи в изучении клинических и нейровизуализационных проявлений диссекции, до настоящего времени остается открытым и малоизученным вопрос о причине развития диссекции. Зарубежные исследователи отмечают наличие слабости стенки артерий, кровоснабжающих головной мозг. В связи с редкостью аутопсий, однако, ее причина остается неясной хотя авторы констатируют патологию соединительной ткани $[8,9]$. Поиск мутаций в гене коллагена, как причины слабости сосудистой стенки у больных с диссекцией, не дал результатов [10, 11].

Целью работы было проанализировать следующие аспекты диссекции ВСА/ПА: 1) морфологические изменения стенки артерий, кровоснабжающих головной мозг; 2) клинические признаки слабости соединительной ткани и биомаркеры ее повреждения; 3) основные факторы, провоцирующие диссекцию.

\section{ПАЦИЕНТЫ И МЕТОДЫ}

В течение 2000-2018 гг. обследовали 271 больного (из них 54\% женщин, 46\% мужчин; средний возраст $37,0 \pm 10$ лет) с диссекцией ВСА/ПА. Критерий включения пациентов в исследование: верификация ИМГ с помощью нейровизуализации и/или обнаружение патогномоничных для диссекции ангиографических данных. Критерии исключения: травматическая диссекция ВСА/ПА; отсутствие нейровизуализационной верификации при типичных для диссекции клинических проявлениях. До развития диссекции все больные считали себя практически здоровыми. Во всех случаях диссекция была спонтанной и клинически проявлялась ишемическим инсультом (63\%), преходящим нарушением мозгового кровообращения (9\%), изолированной шейной/головной болью (27\%), изолированным поражением каудальной группы нервов (1\%). Локализация диссекции была следующей: ВСА у 139 больных (51\%), ПА - у 116 больных (43\%), ВСА + ПА у 16 больных (6\%). У 59 больных (22\%) имелись множественные диссекции: поражение обеих ПА, обеих ВСА или их сочетание. Гистологическое исследование артерий, кровоснабжающих головной мозг, проводили сотрудники лаборатории патологической анатомии Научного центра неврологии. В 4 случаях диссекции ВСА, завершившейся летальным исходом вследствие обширного инфаркта головного мозга, проведено исследование как расслоенных, так и нерасслоенных артерий, кросовнабжающих головной мозг. Еще в одном случае был исследован фрагмент ВСА, полученный в ходе реконструктивной операции на ВСА, осложнившейся ее диссекцией с развитием ишемического инсульта. Окраску гистологических препаратов проводили гематоксилином и эозином, фукселином по методу Вейгерта, по методу Косса для выявления солей кальция и по методу ван Гизона.

Клинические признаки дисплазии соединительной ткани (ДСТ), выбранные из диагностических критериев наследственных заболеваний соединительной ткани (48 признаков), были проанализированы у 82 больных с диссекцией ВСА/ПА. Каждый признак оценивали как положительный (1 балл) или отсутствующий (0 баллов). Кроме того, у всех больных оценивали наличие головной боли в анамнезе. Контрольную группу составили 40 здоровых добровольцев (средний возраст - 38,5 \pm 6,6 лет, из них 62,5\% женщин). Серологические биомаркеры ДСТ (матриксную металлопротеиназу 9 - ММП-9, тканевой ингибитор металлопротеиназы-1 - ТИМП-1), гидроксипролин, сульфатированные гликозаминогликаны), а также фактор роста фибробластов 21 (ФРФ21) исследовали однократно иммуноферментным методом (ELISA). Орозомукоид определяли на автоматическом биохимическом анализаторе Konelab 30IPrime (Thermo Fisher Scientific Oу; Финляндия) у 82 больных. Контрольную группу составили 25 здоровых добровольцев (средний возраст - 36,9 \pm 6,6 лет, женщин - 60,1\%). Провоцирующие факторы диссекции, частоту ее рецидивов и сезонное распределение по месяцам оценивали у всех больных.

Статистическую обработку результатов проводили с помощью программного пакета IBM SPSS Statistics 23.0 (IBM; США). Количественные переменные представляли в виде среднего и стандартного отклонений, качественные и порядковые переменные в виде частоты и доли в процентах. Для проверки нормальности распределения количественного признака использовали критерий Шапиро-Уилка. Для сравнения качественных переменных использовали точный критерий Фишера. Для проверки гипотез о различии использовали однофакторный дисперсионный анализ (ANOVA). Тестирование гомоскедастичности остатков модели проводили методом Голдфелда-Куандта. Во всех случаях применение ANOVA оказалось адекватным. Статистически значимыми считали результаты при $p<0,05$. Выявление значимых для диссекции признаков ДСТ при помощи бинарной логистической регрессии проводили следующим образом: из всех признаков методом последовательного набора по Вальду отобрали значимые. После этого с учетом значимости различий по разным признакам ДСТ между пациентами и группой контроля (Хи-квадрат) проводили улучшение качества модели включением дополнительных признаков. Таким образом, были отобраны признаки ДСТ, характерные для диссекции ВСА и ПА. При одновременном наличии четырех основных и двух дополнительных признаков была достигнута максимальная предсказательная способность регрессионной модели, что позволяло 
выбрать именно такое сочетание признаков ДСТ в качестве диагностически значимых для диссекции ВСА и ПА.

\section{РЕЗУЛЬТАТЫ ИССЛЕДОВАНИЯ}

\section{Морфологические изменения артерий, кровоснабжающих головной мозг}

При макроскопическом исследовании было отмечено расширение и уплотнение расслоенных артерий, что делало их внешне сходными с артериями, обтурированными тромбами. При гистологическом исследовании экстраинтракраниальных артерий было обнаружено изменение внутренней эластической мембраны в виде участков ее истончения, расслоения, выпрямления с исчезновением физиологической извитости, очаговым обызвествлением. На некоторых участках эластическая мембрана полностью отсутствовала. Изменения средней оболочки были представлены ее неравномерной толщиной с зонами резкого истончения, уменьшением числа миоцитов, их неправильной ориентировкой, некрозом, наличием участков фиброза и склероза, уменьшением количества эластических волокон. Указанные изменения носили распространенный характер и обнаруживались не только в артериях, подвергнувшихся диссекции, но и в остальных, внешне неизмененных экстра- и интракраниальных артериях головного мозга (см. рис.).

\section{Клинические признаки дисплазии соединительной ткани и ее биомаркеры у больных с диссекцией ВСА/ПА}

Изучение 48 признаков ДСТ показало, что они более выражены у больных с диссекцией ВСА/ПА (средняя сумма баллов - 7,9 $\pm 3,6)$, чем в контроле $(6 \pm 2,5$ балла; $p=0,0039)$, причем у женщин их выраженность была больше (8,73 \pm 3,0 балла), чем у мужчин 6,4 \pm 2,5; $p=0,05)$. Достоверно чаще, чем в контроле, у больных с диссекцией ВСА/ПА встречались следующие из 48 оцененных признаков ДСТ: артериальная гипотония (51\% vs $20 \% ; p<0,012)$, склонность к образованию синяков (40\% vs 10\%; $p=0,011)$; широкие атрофические рубцы после повреждения кожи и операций (22,5\% vs 0\%; $p=0,019)$; тонкая кожа, через которую просвечивают вены $(28,75 \%$ vs 5\%; $p=0,034)$; арковидное небо $(20 \%$ vs $0 \% ; p=0,034)$; склонность к запорам (30\% vs $10 \%$; $p=0,05)$; носовые кровотечения $(33,75 \%$ vs $15 \% ; p=0,043)$; голубые склеры глаз (20\% vs $5 \%$; $p=0,05)$. Кроме того, у больных с диссекцией ВСА/ПА, чаще, чем в контроле (60\% vs 35\%; $p=0,02)$, в анамнезе отмечена головная боль. В соответствии со статистической значимостью выделенные восемь признаков ДСТ и головная боль были разделены на основные (артериальная гипотония, склонность к синякам, широкие атрофические рубцы на коже после ее повреждения, головная боль в анамнезе) и дополнительные (тонкая кожа, носовые кровотечения, склонность к запорам, голубые склеры, арковидное небо).

При наличии у больного четырех основных и двух дополнительных диагностических признаков согласно регрессионной модели может быть достигнута максимальная предсказательная способность в отношении возможности развития диссекции, в первую очередь, как причины ишемического инсульта (77\%), при наличии только четырех основных признаков предсказательная точность модели составляет $75 \%$.

\section{Биологические маркеры повреждения соединительной ткани}

У больных с диссекцией ВСА/ПА было выявлено повышение MMP-9 (384 \pm 69,3 нг/мл vs 203,1 \pm 60,5 в контроле; $p<0,0005)$, ТИМП-1 (393,9 \pm 63,4 нг/мл vs $134,4 \pm$ 30,8 в контроле; $p<0,0005)$, сульфатированных гликозаминогликанов $(6,2 \pm 1,4$ мкг/мл vs 4,5 $\pm 0,8$ в контроле; $p<0,0005)$, орозомукоида (121,6 $\pm 27,8$ мг/дл vs $88,8 \pm 17,4$ в контроле; $p<0,0005)$. Уровень гидроксипролина
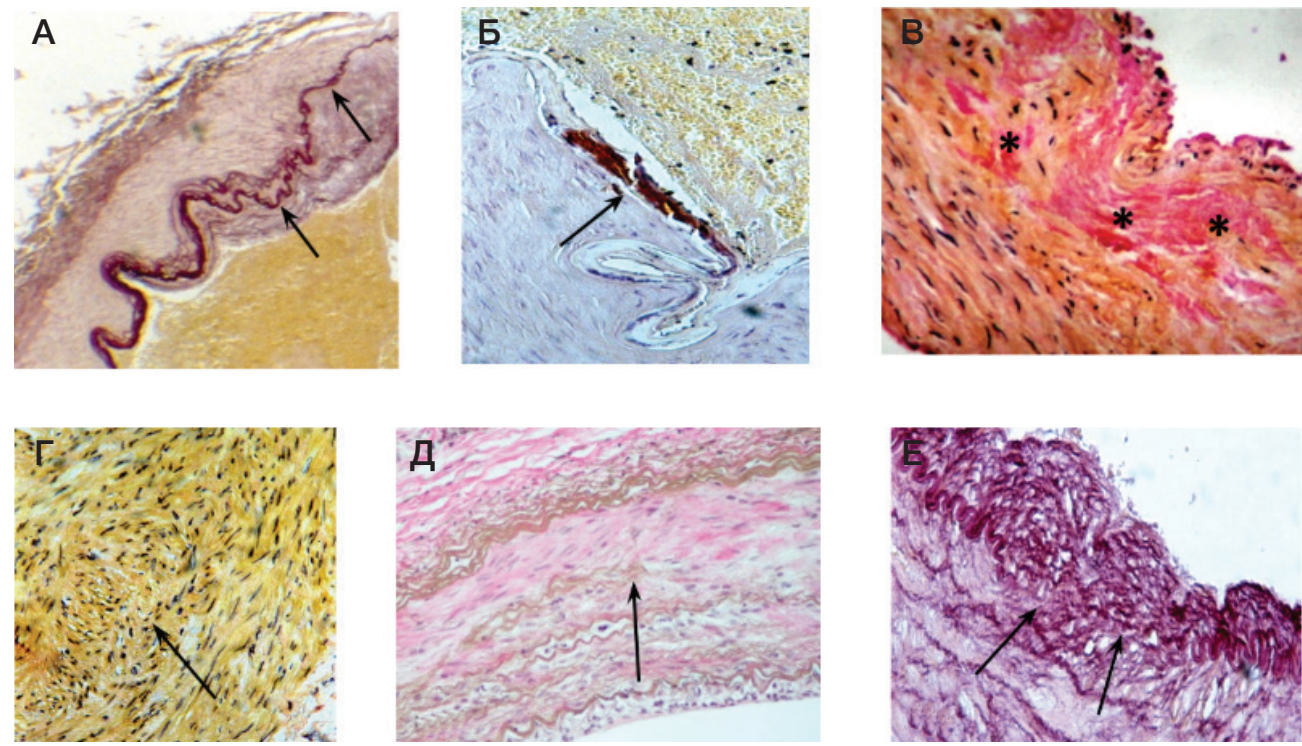

Рисунок. Диспластические изменения стенок внутренних сонных и позвоночных артерий: А. Истончение внутренней эластической мембраны и ее расслоение в сифоне расслоенной ВСА (стрелки). Окраска фукселином по методу Вейгерта. Увеличение х100. Б. Участок обызвествления внутренней эластической мембраны в сифоне расслоенной ВСА (стрелка). Окраска по методу Косса для выявления солей кальция. Увеличение х200. В. Очаговый фиброз (звездочка) в средней оболочке экстракраниального отдела расслоенной ВСА. Окраска по методу ван Гизона. Увеличение х200. Г. Участок средней оболочки сифона расслоенной ВСА с неправильной ориентировкой миоцитов (стрелка). Окраска по методу ван Гизона. Увеличение х200. Д. Участки фиброза и уменьшения числа эластических волокон в средней оболочке нерасслоенной внутренней сонной артерии (стрелка). Окраска по методу ван Гизона. Увеличение х200. Е. Отсутствие фрагмента внутренней эластической мембраны (стрелки) в нерасслоенной позвоночной артерии. Окраска фукселином по методу Вейгерта. Увеличение х200 
был снижен $(604,9 \pm 350,9$ нг/мл vs 1293,6 \pm 214,5 в контроле; $p<0,0005)$ (табл. 1). Уровень ММП-9 был выше при расслоении нескольких артерий (400,5 \pm 71,5 нг/мл), чем одной ВСА $(375,5 \pm 71,55$ нг/мл; $p<0,03)$ или диссекции одной ПА (369,3 \pm 68,6 нг/мл; $p<0,08)$. Уровень ТИМП-1 при множественных диссекциях также был выше (422,2 \pm 53,8 нг/Мл), чем при диссекции одной ВСА (378,5 \pm 62,3 нг/Мл; $p<0,024)$ или одной ПА $(373,6 \pm 60,6$ нг/мл; $p<0,008)$. Уровень сульфатированных гликозаминогликанов при множественных диссекциях составил 6,8 \pm 1,2 мкг/мл, при повреждении одной ВСА или одной ПА - 5,8 \pm 1,3 мкГ/Мл и 5,7 $\pm 1,5$ мкг/Мл соответственно ( $p<0,029$ и 0,016). Уровень орозомукоида при множественных диссекциях был выше (129,7 \pm 34 мг/дл), чем при диссекции одной ВСА $(118,6 \pm 25,3 ; p<0,039)$ и одной ПА (112,6 \pm 20,6 мг/дл; $p<0,011)$ (табл. 2). В первые 3 месяца заболевания уровни орозомукоида и гидроксипролина были выше, чем в более поздние сроки. Уровень ТИМП-1, напротив, был выше в позднем периоде диссекции. ФРФ-21 - биомаркер митохондриальной патологии [12] при диссекции был повышен до $536 \pm 250$ пг/Мл (контроль $-204 \pm 50$ пг/мл; $p<0,0005)$.

\section{Провоцирующие факторы развития диссекции}

Наиболее часто (42\% случаев) провоцирующими фракторами диссекции были движения в шейном отделе позвоночника (наклоны, повороты, неудобное вынужденное положение головы, физическое напряжение), которые при диссекции ПА обнаруживали чаще (61\%), чем при диссекции ВСА (27\%; $p<0,0009)$. Предшествовавшая легкая травма головы была отмечена у 10\% больных (ВСА - 14\%, ПА - 5\%; $p<0,05)$. Острая респираторная инфекция, перенесенная в течение месяца до диссекции ВСА/ПА, выявлена у 14\% больных. Контрацептивы перед развитием диссекции принимали $12 \%$ женщин.
Проведенный нами анализ сезонного распределения диссекции ВСА/ПА не выявил статистически значимой разницы в частоте ее развития в разные месяцы. Частота ее встречаемости с января по декабрь была следующей: $9,6 \%, 9,3 \%, 8,1 \%, 4,2 \%, 8 \%, 9,6 \%, 5,9 \%, 10 \%, 9,6 \%$, 8,5\%, 7,0\%, 10,4\%. Ассоциации с перенесенной в предшествующий месяц респираторной инфекцией обнаружено не было.

\section{Рецидивы диссекции}

Развитие повторной диссекции (рецидив), вовлекающей другую артерию, как правило, одноименную противоположную, было зарегистрировано у 12\% больных. Bce рецидивы были верифицированы с помощью нейровизуализации. В большинстве случаев они происходили в первые 35 дней заболевания (7,3\%), в последующие месяцы (до года) их частота составила 1,5\%, в дальнейшем рецидивы развивались через 5-10 лет у 3,3\% больных.

\section{ОБСУЖДЕНИЕ РЕЗУЛЬТАТОВ}

Комплексное клинико-лабораторно-морфологическое исследование у больных с диссекцией ВСА/ПА выявило признаки патологии соединительной ткани, что отмечали и другие авторы $[8,9]$. Обнаруженные изменения не соответствуют известным наследственным синдромам патологии соединительной ткани (Элерса-Данло, Марфана, гипермобильности суставов) и могут, на наш взгляд, быть рассмотрены как недифференцированные. В стенках экстра- и интракраниальных артерий, как расслоенных, так и внешне неизмененных, они были представлены выраженными диспластическими изменениями, которые и лежали в основе слабости артериальной стенки, предрасполагая ее к диссекции. Комплекс изменений,

Таблица 1. Биомаркеры ДСТ у больных с диссекцией BCA/ПА и в контроле (однофакторный дисперсионный анализ, АNOVA)

\begin{tabular}{|c|c|c|}
\hline Показатели (среднее \pm SD) & $\begin{array}{c}\text { Диссекция } \\
n=82\end{array}$ & $\begin{array}{c}\text { Контроль } \\
n=25 \\
p\end{array}$ \\
\hline ММП-9, нг/мл & $384 \pm 69,3$ & $203,1 \pm 60,5$ \\
\hline ТИМП-1, нг/мл & $393,9 \pm 63,4$ & $134,4 \pm 30,8$ \\
\hline Орозомукоид, мг/дл & $121,6 \pm 27,8$ & $88,8 \pm 17,4$ \\
\hline Сульфатированные гликозаминогликаны, мкг/мл & $6,2 \pm 1,4$ & $4,5 \pm 0,8$ \\
\hline Гидроксипролин, нг/мл & $604,9 \pm 350,9$ & $<0,0005$ \\
\hline
\end{tabular}

Примечание: $p$ - уровень значимости; SD — стандартное отклонение (standard deviation).

Таблица 2. Биомаркеры ДСТ в зависимости от локализации и распространенности диссекции (однофакторный дисперсионный анализ с апостериорными тестами, сравнениями по методу Шесфе)

\begin{tabular}{|c|c|c|c|c|}
\hline \multirow[b]{2}{*}{ Лабораторный показатель (среднее \pm SD) } & Группа 1 & Группа 2 & Группа 3 & \multirow[b]{2}{*}{$p$} \\
\hline & $\begin{array}{c}\text { Диссекция ВСА } \\
n=28\end{array}$ & $\begin{array}{c}\text { Диссекция ПА } \\
n=27\end{array}$ & $\begin{array}{c}\text { Диссекция более } 1 \text { артерии } \\
n=27\end{array}$ & \\
\hline \multirow{2}{*}{ ММП-9, нг/мл } & \multirow{2}{*}{$375,5 \pm 71,5$} & \multirow{2}{*}{$369,3 \pm 68,6$} & \multirow{2}{*}{$400,5 \pm 71,5$} & Группа 1 и 3 0,03 \\
\hline & & & & Группа 2 и 3 0,008 \\
\hline \multirow{2}{*}{ ТИМП-1, нг/мл } & \multirow{2}{*}{$378,5 \pm 62,3$} & \multirow{2}{*}{$373,6 \pm 60,6$} & \multirow{2}{*}{$422,2 \pm 53,8$} & Группа 1 и 3 0,024 \\
\hline & & & & Группа 2 и 3 0,008 \\
\hline \multirow{2}{*}{ Сульфатирова-нные гликозамино-гликаны, мкг/мл } & \multirow{2}{*}{$5,8 \pm 1,3$} & \multirow{2}{*}{$5,7 \pm 1,5$} & \multirow{2}{*}{$6,8 \pm 1,2$} & Группа 1 и 3 0,029 \\
\hline & & & & Группа 2 и 3 0,016 \\
\hline \multirow{2}{*}{ Орозомукоид, мг/дл } & \multirow{2}{*}{$118,6 \pm 25,3$} & \multirow{2}{*}{$112,6 \pm 20,6$} & \multirow{2}{*}{$129,7 \pm 34$} & Группа 1 и 30,039 \\
\hline & & & & Группа 2 и 3 0,011 \\
\hline
\end{tabular}

Примечание: $p$ - уровень значимости; ВСА — внутренняя сонная артерия; ПА — позвоночная артерия; SD — стандартное отклонение. 
обнаруженных при микроскопическом исследовании экстра- и интракраниальных артерий, по нашему мнению, характерен для фибромышечной дисплазии (ФМД) [13-16]. В связи с этим уместно отметить, что ФМД, международные диагностические критерии которой были опубликованы в 2019 г. [17], имеет много сходных черт с диссекцией ВСА/ПА. Так, при ФМД часто развиваются диссекции различных артерий, включая ВСА/ПА, выявляются аневризмы и извитость артерий, которые обнаруживают и у больных с диссекцией ВСА/ПА. Многие больные с ФМД [17], как и больные с диссекцией [18], страдают головными болями. Частота наследственной отягощенности при ФМД (1,9-7,3\%) [17] и диссекции ВСА/ПА (2\%) [19] сходна. Полногеномное ассоциативное исследование больных с ФМД выявило полиморфизм гена PHACTR1 [20], который был обнаружен и при диссекции ВСА/ПА во время многоцентрового международного обследования 1393 больных, включавших и наших пациентов [21]. Как при диссекции [1, 5, 22], так и при ФМД [17], отмечают неблагоприятное влияние приема контрацептивов. Несмотря на отмеченное сходство между больными с ФМД и диссекцией, при последней отсутствует ключевой диагностический ангиографический признак ФМД четкообразное изменение артерий (чередование участков сужения и расширения). В связи с этим вопрос наличия ФМД при отсутствии типичного изменения ангиографической картины нуждается в дальнейшем изучении. Косвенным подтверждением такой возможности является наблюдение за одним из наших больных, у которого на протяжении 10 лет трижды развивались повторные диссекции обеих ВСА и правой ПА, а также инфаркт левой почки. При КТА почечных артерий обнаружены характерные для ФМД четкообразные изменения, тогда как в ВСА и ПА их не было. Согласно современным диагностическим критериям ФМД, при наличии у больного типичных изменений хотя бы в одном сосуде, развитие диссекции, выявление извитости или аневризм в других бассейнах необходимо рассматривать как проявления ФМД. Именно такая ситуация сложилась у нашего больного.

Причина диспластических изменений в артериальной стенке, морфологически сходных с таковыми при ФМД, у больных с диссекцией окончательно не ясна. Согласно нашей гипотезе, дисплазия связана с митохондриальными нарушениями [23, 24]. Выявленное нами повышение ФРФ-21, биомаркера митохондриальной патологии [12], у больных с диссекцией ВСА/ПА косвенно подтверждает эту концепцию. Патогенез ФМД также остается нераскрытым, некоторые авторы придают значение повышению уровня трансформирующего фрактора роста $\beta 1$ и $\beta 2$ (TGF- $\beta 1$ и TGF- $\beta 2)$, продуцируемого фибробластами [25].

Оценка клинических признаков ДСТ показала, что они более выражены у больных с диссекцией ВСА/ПА, чем в контроле, что отмечают и другие авторы [9]. Это указывает на распространенный характер повреждения соединительной ткани, что согласуется с электронномикроскопическим исследованием биоптатов кожи [8, 24]. Отмеченная нами большая встречаемость признаков ДСТ у женщин позволяет предположить, что в их развитии играют роль женские половые гормоны. Наряду с клиническими признаками ДСТ у больных с диссекцией оценивали наличие головной боли в анамнезе, поскольку, согласно нашим исследованиям, она часто связана с диспластическими изменениями стенки экстра- и интракраниальных артерий [18, 22], тогда как в зарубежной литературе ее трактуют как мигрень [5]. Практическое значение анализа признаков ДСТ у больных с инсультом состоит в том, что они могут быть использованы при уточнении причины инсульта в молодом возрасте, особенно В ситуации, когда недоступно нейровизуализационное исследование. Статистическая обработка данных показала, что при наличии четырех основных и двух дополнительных признаков ДСТ вероятность диссекции как причины ИИ в молодом возрасте достигает 77\% [22].

Наличие распространенного повреждения соединительной ткани у больных с диссекцией ВСАЛПА было подтверждено изучением биомаркеров ДСТ. Найденное нами повышение ММП-9, сульфатированых гликозаминогликанов и орозомукоида свидетельствовало о повреждении соединительной ткани (коллагена, межклеточного вещества) и развитии воспалительной реакции в артериальной стенке. Лабораторные признаки воспаления отмечают и другие авторы, связывая их с предшествующей инфекцией, играющей роль провокации диссекции [26]. С этим согласуется более высокий уровень орозомукоида, маркера воспаления, отмеченный нами в первые 3 месяца заболевания. При расслоении 2-3 артерий биомаркеры ДСТ были выше, что указывает на более выраженное повреждение соединительной ткани, обусловившее развитие множественных диссекций. Уровень ТИМП-1, фермента, блокирующего матриксные протеиназы, при давности диссекции более 3 месяцев, был выше, чем в первые 3 месяца, что, по-видимому, отражало переход процесса в репаративную стадию.

В развитии диссекции ВСА и ПА в условиях имеющейся дисплазии их стенки большое значение отводят провоцирующим факторам. К основным из них относят повороты головы, ее травму, как правило, легкую, физическую нагрузку, острую респираторную инфекцию, перенесенную в течение предшествующего месяца, реже прием гормональных контрацептивов, повышение АД, прием алкоголя непосредственно перед развитием диссекции, употребление препаратов для понижения веса, частые и длительные перелеты на самолете [1, 5, 22]. Наиболее распространенными провоцирующими факторами у наших больных были движения в шее и физическая нагрузка (42\%), которые при диссекции ПА встречались чаще (61\%), чем при диссекции ВСА (27\%). В зарубежной литературе обсуждают провоцирующую роль мануальной терапии [5], которая имела место и у отдельных наших больных, а также травмы шеи [6, 7]. Наибольшая уязвимость ПА при поворотах головы объясняется ее анатомическими особенностями, а именно фиксацией в позвоночном канале. В условиях пониженной эластичности артериальной стенки вследствие ее дисплазии натяжение артерии во время поворота головы приводит к надрыву интимы в первую очередь в местах ее фиксации к окружающим структурам. Легкая травма головы чаще предшествует диссекции ВСА (14\%), чем ПА (5\%), что отмечают и зарубежные исследователи [5]. Во время травмы головы происходит смещение головного мозга относительно костей черепа, что приводит к натяжению интракраниального отдела ВСА и надрыву интимы в месте фиксации ВСА к костным структурам при входе в канал пирамидки височной кости, где чаще всего и локализуется ИМГ.

Инфекционное, как правило, острое респираторное, заболевание, перенесенное в течение месяца, предшествовавшего диссекции ВСА/ПА, было отмечено у 14\% наших больных. При инсультах иного генеза предшествующая инфекция встречается реже, что 
подтверждает ее роль в развитии диссекции [27]. Инфекционное заболевание сопровождается повышением уровня протеолитических ферментов лейкоцитарного происхождения и матриксных металлопротеиназ, которые вызывают деградацию белков экстраклеточного матрикса сосудистой стенки и повреждение эндотелия [26, 27]. Обнаруженное нами повышение уровня МMT-9 и орозомукоида у больных с диссекцией подтверждает этот механизм провоцирующего действия инфекции.

Прием контрацептивов как фактор, провоцирующий диссекцию, был выявлен у 12\% обследованных нами женщин, что несколько реже, чем в европейских исследованиях [6, 7]. Гормональные препараты, повидимому, усиливают диспластические изменения артериальной стенки, предрасполагая ее к расслоению.

Некоторые исследователи придают значение сезонным изменениям климата на основании более частого развития диссекции в холодный период года, предполагая при этом, что сезонность реализует свое влияние через характерное для этого периода года повышение пульсового АД и более частое развитие респираторных инфекционных заболеваний $[28,29]$. Проведенный нами анализ сезонного распределения случаев возникновения диссекции ВСА ПА у 271 больного не выявил статистически значимой разницы в частоте ее развития в разные месяцы, а также и ассоциации с инфекционными заболеваниями. Метеорологическая неустойчивость, в первую очередь изменение атмосферного давления, характерна для всех сезонов года в средней полосе России, где проживало большинство наших больных. Возможно, что патогенетически значимым метеорологическим фактором было снижение атмосферного давления, которое влечет за собой расширение артерии. В этой ситуации в месте ее наименьшей эластичности, обусловленной участками фиброза и неправильной ориентировки миоцитов, может произойти надрыв интимы.

Несмотря на относительно понятный механизм действия большинства провоцирующих факторов, остается неясным, почему в условиях их частой встречаемости в повседневной жизни (повороты головы, физическая нагрузка, респираторные инфекции и др.) и наличии у больных, согласно морфологическим исследованиям, распространенных признаков дисплазии артерий, кровоснабжающих головной мозг, рецидивы диссекции происходят редко. Так, частота рецидивов, верифицированных с помощью нейровизуализации, у наших больных составила 12,1\%, причем в большинстве случаев они происходили в первые 35 дней заболевания (7,3\%), тогда как в последующие месяцы (до года) их частота была значительно меньше (1,5\%), в дальнейшем рецидивы отмечены у 3,3\% больных через 5-10 лет от развития первой диссекции. Действительная частота повторных диссекций в первые дни-недели очевидно больше, так как у 22\% наших больных при первом нейровизуализационном обследовании обнаруживали расслоение более одной артерии. По данным зарубежных авторов, рецидивы чаще возникают в первые недели заболевания, и их частота составляет менее 3\%. Частота рецидивов в поздние сроки среди 200 больных, наблюдавшихся другими авторами в течение 7,4 лет, составила 7\% [30].

Наибольшая частота рецидивов в первый месяц после развития диссекции и редкость ее развития в более поздние сроки позволяют предположить, что существуют «критические» периоды снижения прочности артериальной стенки, способствующие развитию диссекции. Наряду с инфекцией и гормональными изменениями, отмечающимися у небольшой части больных, по-видимому, имеют значение и какието эндогенные обменные нарушения, приводящие $\mathrm{k}$ деградации экстраклеточного матрикса, некрозу миоцитов средней оболочки артериальной стенки, который был обнаружен нами при гистологическом исследовании экстра- и интракраниальных артерий, а также к нарушению трофической функции фибробластов $[14,13]$. Характер предполагаемых обменных нарушений не известен. С позиции нашей концепции митохондриальной цитопатии как причины дисплазии сосудистой стенки [23] интересна параллель с энергетическими кризами, характерными для митохондриальных заболеваний, которые могли бы объяснить редкость поздних рецидивов диссекции и их частое развитие в ранние сроки.

\section{ВЫВОДЫ}

1. Слабость сосудистой стенки, обусловленная ее дисплазией, предрасполагает к диссекции ВСА/ПА, морфологическая характеристика изменений стенки соответствует ФМД. 2. Под влиянием эндогенных и экзогенных факторов выраженность дисплазии усиливается до критического состояния, что спонтанно или под действием провоцирующих факторов может приводить к диссекции. 3. Продолжительность критического периода немного больше месяца, во время которого чаще всего и происходят рецидивы. Для их предотвращения в этот период необходимо избегать резких движений головой, с целью чего рекомендуется ношение шейного ортеза. 4. Для выявления клинически асимптомной повторной диссекции через месяц после начала заболевания показано проведение повторной МРТ артерий шеи в режиме T1fs. 5. Изучение генеза дисплазии артериальной стенки при диссекции ВСА/ПА поможет разработать патогенетически обоснованное профилактическое лечение наряду с применением препаратов, улучшающих трофику соединительной ткани.

\section{Литература}

1. Калашникова Л. А., Добрынина Л. А. Диссекция артерий головного мозга: ишемический инсульт и другие клинические проявления. М.: Изд-во «Вако», 2013; 208 с.

2. Robertson JJ, Koyfman A. Cervical artery dissection: a review. J Emerg Med. 2016; 51 (5): 508-18. PubMed PMID: 27634674.

3. Hakimi R, Sivakumar S. Imaging of Carotid Dissection. Curr Pain Headache Rep. 2019; 23 (1): 2. PubMed PMID: 30661121.

4. Калашникова Л. А., Добрынина Л. А., Древаль М. В., Доронина Е. В., Назарова М. А. Шейная и головная боль как

единственное проявление диссекции внутренней сонной и позвоночной артерий. Журнал неврологии и психиатрии им. Корсакова. 2015; (3): 9-16. PubMed PMID: 24300790.

5. Débette S. Pathophysiology and risk factors for cervical artery dissection: what have we learned from large hospital-based cohorts? Curr Opin Neurol 2014; (1): 20-8. PubMed PMID: 24300790.

6. von Babo M, De Marchis GM, Sarikaya H, Stapf C, Buffon F, Fischer $U$, et al. Differences and similarities between spontaneous 
dissections of the internal carotid artery and the vertebral artery. Stroke. 2013; 44 (6): 1537-42. PubMed PMID: 23632978.

7. Debette S, Grond-Ginsbach C, Bodenant M, Kloss M, Engelter S, Metso, et al. Differential features of carotid and vertebral artery dissections: the CADISP study. Neurology. 2011; 77 (12): 117481. PubMed PMID: 21900632

8. Brandt T, Hausser I, Orberk E, Grau A, Hartschuh W, AntonLamprecht I, et al. Ultrastructural connective tissue abnormalities in patients with spontaneous cervicocerebral artery dissections. Ann Neurol. 1998; (44): 281-285. PubMed PMID: 9708556.

9. Giossi A, Ritelli M, Costa P, Morotti A, Poli L, Del Zotto E, et al. Connective tissue anomalies in patients with spontaneous cervical artery dissection. Neurology. 2014; 83 (22): 2032-7. PubMed PMID: 25355826.

10. Grond-Ginsbach C, Thomas-Feles C, Werner I, Weber R, Wigger F, Hausser I, et al. Mutations in the tropoelastin gene (ELN) were not found in patients with spontaneous cervical artery dissections. Stroke. 2000; 31 (8): 1935-8. PubMed PMID: 10926960.

11. Grond-Ginsbach C, Weber R, Haas J, Orberk E, Kunz S., Busse O, et al. Mutations in the COL5A1 coding sequence are not common in patients with spontaneous cervical artery dissections. Stroke. 1999; 30 (9):1887-90. PubMed PMID: 10471441.

12. Lehtonen JM, Forsström S, Bottani E, Viscomi C, Baris OR, Isoniemi $\mathrm{H}$, et al. FGF 21 is a biomarker for mitochondrial translation and mtDNA maintenance disorders. Neurology. 2016; 87 (22): 2290-9. PubMed PMID: 27794108.

13. Калашникова Л. А., Гулевская Т. С., Ануфриев П. Л., Гнедовская Е. В., Коновалов Р. Н., Пирадов М. А. Ишемический инсульт в молодом возрасте, обусловленный стенозирующим расслоением (диссекцией) интракраниального отдела внутренней сонной артерии и ее ветвей (клиникоморфологическое наблюдение). Анналы клинической и экспериментальной неврологии. 2009; 3 (1): 18-24.

14. Anderson RM, Schechter MM. A case of spontaneous dissecting aneurysm of the internal carotid artery. J Neurol Neurosurg Psychiatry. 1959; (22): 195-201. PMID: 13793447.

15. Southerland AM, Meschia JF, Worrall BB. Shared associations of nonatherosclerotic, large-vessel, cerebrovascular arteriopathies: considering intracranial aneurysms, cervical artery dissection, moyamoya disease and fibromuscular dysplasia. Curr Opin Neurol. 2013; (26): 13-28. PubMed PMID: 23302803.

16. Калашникова Л. А., Чайковская Р. П., Гулевская Т. С., Добрынина Л. А., Губанова М. В., Древаль М. В., Максимова М. Ю. Разрыв интимы при дисплазии стенки средней мозговой артерии, осложнившийся тромбозом и развитием тяжелого ишемического инсульта (клинико-морфологическое наблюдение). Журнал неврологии и психиатрии им. С. С. Корсакова. 2018; 118 (3): 9-14. PubMed PMID: 29798974.

17. Gornik HL, Persu A, Adlam D, Aparicio LS, Azizi M, Boulanger M, et al. First International Consensus on the diagnosis and management of fibromuscular dysplasia. Vascular Medicine. 2019; 24 (2): 16489. PubMed PMID: 306448921.

18. De Giuli V, Grassi M, Lodigiani C, Patella R, Zedde M, Gandolfo C, et al. Association between migraine and cervical artery dissection: the Italian project on stroke in young adults. JAMA Neurol. 2017; 74 (5) 512-18. PubMed PMID: 28264095

19. Schievink WI, Mokri B, Piepgras DG, Kuiper JD. Recurrent spontaneous artery dissections. Risk in familial versus nonfamilial disease. Stroke. 1996; 27 (4): 622-4. PubMed PMID: 8614918.

20. Kiando SR, Tucker NR, Castro-Vega LJ, Katz A, D'Escamard V, Tréard C, et al. PHACTR1 is a genetic susceptibility locus for fibromuscular dysplasia supporting its complex genetic pattern of inheritance. PLOS Genet. 2016; 12 (10): e1006367. PubMed PMID: 27792790

21. Debette S, Kamatani Y, Metso TM, Kloss M, Chauhan G, Engelter ST, et al. Common variation in PHACTR1 is associated with susceptibility to cervical artery dissection. Nat Genet. 2015; 47 (1): 78-83. PubMed PMID: 25420145

22. Губанова М. В., Калашникова Л. А., Добрынина Л. А. Шамтиева К. В., Бердалин А. Б. Маркеры дисплазии соединительной ткани при диссекции магистральных артерий головы и провоцирующие факторы диссекции. Анналь клинической и экспериментальной неврологии. 2017; 11 (4): 19-28. DOI: 10.18454/ACEN.2017.4.2.

23. Hausser I, Muller U, Engelter S, Lyrer P, Pezzini A, Padovani A, et al. Different types of connective tissue alterations associated with cervical artery dissections. Acta Neuropathol. 2004; 107 (6): 509-14. PubMed PMID: 15067552.

24. Сахарова А. В., Калашникова Л. А., Чайковская Р. П., Добрынина Л. А., Мир-Касимов М. Ф. Назарова М. А. и др. Морфологические и ультраструктурные признаки митохондриальной цитопатии в скелетных мышцах и микрососудах мышц и кожи при диссекции церебральных артерий, ассоциированной с мутацией А3243G в митохондриальной ДНК. Архив патологии. 2012; 74 (2): 51-6.

25. Ganesh SK, Morissette R, Xu Z, Schoenhoff F, Griswold BF, Yang J, et al. Clinical and biochemical profiles suggest fibromuscular dysplasia is a systemic disease with altered TGF- $\beta$ expression and connective tissue features. FASEB J. 2014; 28 (8): 3313-24. PubMed PMID: 24732132.

26. Grond-Ginsbach C, Giossi A, Aksay SS, Engelter ST, Lyrer PA, Metso TM, et al. Elevated peripheral leukocyte counts in acute cervical artery dissection. Eur J Neurol. 2013; 20 (10):1405-10. PubMed PMID: 23879551.

27. Guillon B, Berthet K, Benslamia L, Bertrand M, Bousser MG Tzourio C. Infection and the risk of spontaneous cervical artery dissection: a case-control study. Stroke. 2003; 34 (7): 79-81. PubMed PMID: 12805497

28. Schievink WI, Wijdicks EF, Kuiper JD. Seasonal pattern of spontaneous cervical artery dissection. J Neurosurg. 1998; 89 (1): 101-3. PubMed PMID: 9647179.

29. Kloss M, Metso A, Pezzini A, Leys D, Giroud M, Metso TM, et al. Towards understanding seasonal variability in cervical artery dissection (CeAD). J Neurol. 2012; 259 (8):1662-7. PubMed PMID: 22286657

30. Schievink WI, Mokri B, O'Fallon WM. Recurrent spontaneous cervical-artery dissection. N Engl J Med. 1994; 330 (6): 393-7. PubMed PMID: 8284004

\section{References}

1. Kalashnikova LA, Dobrynina LA. Dissekcija arterij golovnogo mozga: ishemicheskij insul't i drugie klinicheskie projavlenija. M.: Izd-vo «Vako», 2013; 208 s. Russian.

2. Robertson JJ, Koyfman A. Cervical artery dissection: a review. J Emerg Med. 2016; 51 (5): 508-18. PubMed PMID: 27634674.

3. Hakimi R, Sivakumar S. Imaging of Carotid Dissection. Curr Pain Headache Rep. 2019; 23 (1): 2. PubMed PMID: 30661121.

4. Kalashnikova LA, Dobrynina LA, Dreval MV, Doronina EV, Nazarova MA. Shejnaya i golovnaja bol' kak edinstvennoe projavlenie dissekcii vnutrennej sonnoj i pozvonochnoj arterij. Zhurnal nevrologii i psihiatrii im. Korsakova. 2015; (3): 9-16. PubMed PMID: 24300790. Russian.

5. Débette S. Pathophysiology and risk factors for cervical artery dissection: what have we learned from large hospital-based

cohorts? Curr Opin Neurol. 2014; (1): 20-8. PubMed PMID: 24300790.

6. von Babo M, De Marchis GM, Sarikaya H, Stapf C, Buffon F, Fischer $U$, et al. Differences and similarities between spontaneous dissections of the internal carotid artery and the vertebral artery. Stroke. 2013; 44 (6): 1537-42. PubMed PMID: 23632978.

7. Debette S, Grond-Ginsbach C, Bodenant M, Kloss M, Engelter S, Metso, et al. Differential features of carotid and vertebral artery dissections: the CADISP study. Neurology. 2011; 77 (12): 1174 81. PubMed PMID: 21900632.

8. Brandt T, Hausser I, Orberk E, Grau A, Hartschuh W, AntonLamprecht I, et al. Ultrastructural connective tissue abnormalities in patients with spontaneous cervicocerebral artery dissections. Ann Neurol. 1998; (44): 281-285. PubMed PMID: 9708556. 
9. Giossi A, Ritelli M, Costa P, Morotti A, Poli L, Del Zotto E, et al. Connective tissue anomalies in patients with spontaneous cervical artery dissection. Neurology. 2014; 83 (22): 2032-7. PubMed PMID: 25355826.

10. Grond-Ginsbach C, Thomas-Feles C, Werner I, Weber R, Wigger F, Hausser I, et al. Mutations in the tropoelastin gene (ELN) were not found in patients with spontaneous cervical artery dissections. Stroke. 2000; 31 (8): 1935-8. PubMed PMID: 10926960.

11. Grond-Ginsbach C, Weber R, Haas J, Orberk E, Kunz S., Busse O, et al. Mutations in the COL5A1 coding sequence are not common in patients with spontaneous cervical artery dissections. Stroke. 1999; 30 (9):1887-90. PubMed PMID: 10471441.

12. Lehtonen JM, Forsström S, Bottani E, Viscomi C, Baris OR, Isoniemi $\mathrm{H}$, et al. FGF 21 is a biomarker for mitochondrial translation and mtDNA maintenance disorders. Neurology. 2016; 87 (22): 2290-9. PubMed PMID: 27794108.

13. Kalashnikova LA, Gulevskaya TS, Anufriev PL, Gnedovskaja EV, Konovalov RN, Piradov MA. Ischemic stroke in young age due to dissection of intracranial carotid artery and its branches (clinical and morphological study). Annals of Clinical and Experimental Neurology. 2009; 3 (1): 18-24. Russian.

14. Anderson RM, Schechter MM. A case of spontaneous dissecting aneurysm of the internal carotid artery. J Neurol Neurosurg Psychiatry. 1959; (22): 195-201. PMID: 13793447.

15. Southerland AM, Meschia JF, Worrall BB. Shared associations of nonatherosclerotic, large-vessel, cerebrovascular arteriopathies: considering intracranial aneurysms, cervical artery dissection, moyamoya disease and fibromuscular dysplasia. Curr Opin Neurol. 2013; (26): 13-28. PubMed PMID: 23302803.

16. Kalashnikova LA, Chaykovskaya RP, Gulevskaya TS, Dobrynina LA, Gubanova MV, Dreval MV, et al. Intimal rupture of the displastic middle cerebral artery wall complicated by thrombosis and fatal ischemic stroke. Zh Nevrol Psikhiatr Im S S Korsakova. 2018; 118 (3): 9-14. PubMed PMID: 29798974. Russian.

17. Gornik HL, Persu A, Adlam D, Aparicio LS, Azizi M, Boulanger M, et al. First International Consensus on the diagnosis and management of fibromuscular dysplasia. Vascular Medicine. 2019; 24 (2): 16489. PubMed PMID: 306448921

18. De Giuli V, Grassi M, Lodigiani C, Patella R, Zedde M, Gandolfo C, et al. Association between migraine and cervical artery dissection: the Italian project on stroke in young adults. JAMA Neurol. 2017; 74 (5) 512-18. PubMed PMID: 28264095.

19. Schievink WI, Mokri B, Piepgras DG, Kuiper JD. Recurrent spontaneous artery dissections. Risk in familial versus nonfamilial disease. Stroke. 1996; 27 (4): 622-4. PubMed PMID: 8614918.

20. Kiando SR, Tucker NR, Castro-Vega LJ, Katz A, D'Escamard V,
Tréard C, et al. PHACTR1 is a genetic susceptibility locus for fibromuscular dysplasia supporting its complex genetic pattern of inheritance. PLOS Genet. 2016; 12 (10): e1006367. PubMed PMID: 27792790.

21. Debette S, Kamatani Y, Metso TM, Kloss M, Chauhan G, Engelter ST, et al. Common variation in PHACTR1 is associated with susceptibility to cervical artery dissection. Nat Genet. 2015; 47 (1): 78-83. PubMed PMID: 25420145.

22. Gubanova MV, Kalashnikova LA, Dobrynina LA, Shamtieva KV, Berdalin AB. Markery displazii soedinitel'noj tkani pri dissekcii magistral'nyh arterij golovy i provocirujushhie faktory dissekcii. Annaly klinicheskoj i jeksperimental'noj nevrologii. 2017; 11 (4): 19-28. DOI: 10.18454/ACEN.2017.4.2. Russian.

23. Hausser I, Muller U, Engelter S, Lyrer P, Pezzini A, Padovani A, et al. Different types of connective tissue alterations associated with cervical artery dissections. Acta Neuropathol. 2004; 107 (6): 509-14. PubMed PMID: 15067552.

24. Sakharova AV, Kalashnikova LA, Dobrynina LA, Chaykovskaya RP, Mir-Kasimov MF, Nazarova MA, et al. Morphological signs of mitochondrial cytopathy in skeletal muscles and micro-vessels in a patient with cerebral artery dissection associated with MELAS syndrome. Arkhiv patologii. 2010; 74 (2): 51-6. Russian.

25. Ganesh SK, Morissette R, Xu Z, Schoenhoff F, Griswold BF, Yang J, et al. Clinical and biochemical profiles suggest fibromuscular dysplasia is a systemic disease with altered TGF- $\beta$ expression and connective tissue features. FASEB J. 2014; 28 (8): 3313-24. PubMed PMID: 24732132

26. Grond-Ginsbach C, Giossi A, Aksay SS, Engelter ST, Lyrer PA, Metso TM, et al. Elevated peripheral leukocyte counts in acute cervical artery dissection. Eur J Neurol. 2013; 20 (10):1405-10. PubMed PMID: 23879551.

27. Guillon B, Berthet K, Benslamia L, Bertrand M, Bousser MG, Tzourio C. Infection and the risk of spontaneous cervical artery dissection: a case-control study. Stroke. 2003; 34 (7): 79-81. PubMed PMID: 12805497.

28. Schievink WI, Wijdicks EF, Kuiper JD. Seasonal pattern of spontaneous cervical artery dissection. J Neurosurg. 1998; 89 (1): 101-3. PubMed PMID: 9647179.

29. Kloss M, Metso A, Pezzini A, Leys D, Giroud M, Metso TM, et al. Towards understanding seasonal variability in cervical artery dissection (CeAD). J Neurol. 2012; 259 (8):1662-7. PubMed PMID: 22286657

30. Schievink WI, Mokri B, O'Fallon WM. Recurrent spontaneous cervical-artery dissection. N Engl J Med. 1994; 330 (6): 393-7. PubMed PMID: 8284004. 